\title{
DESPESA PÚBLICA E ORDEM SIMBÓLICA: PEC 241 E AS REPRESENTAÇÕES OFICIAIS
}

\section{PUBLIC EXPENDITURE AND SYMBOLIC ORDER: PEC 241 AND THE OFFICIAL REPRESENTATIONS}

\author{
Bruno Moretti*
}

\section{Introdução}

Este artigo aborda o discurso dos agentes oficiais e seus argumentos para a aprovação da Proposta de Emenda Constitucional (PEC 241/2016'1), que limita os gastos públicos à inflação do exercício anterior por até vinte anos. Procura-se mostrar, valendo-se da PEC 241, que os problemas públicos são construídos por meio de operações linguísticas que transformam dados em representações sociais, gerando definições coletivas que tendem a se cristalizar no espaço público, autorizando escolhas políticas.
Para tanto, serão examinados os enunciados dos agentes governamentais de modo a mostrar como eles constroem a palavra oficial, apoiando-se no pensamento econômico convencional e postulando um capital de autoridade, para falar em nome do coletivo. 0 foco do trabalho é a produção do ponto de vista oficial, cujos poderes envolvem a fabricação dos termos em que é definido o domínio público, atribuindo sentido às práticas socialmente autorizadas em correspondência com as representações do interesse coletivo.

Não se presume que apenas os agentes oficiais tenham autoridade para construir as

\footnotetext{
* Doutor em Sociologia pela Universidade de Brasília. Professor visitante do Departamento de Sociologia da UNB (Brasília/DF/BR). E-mail:bmorettil@gmail.com

1. A PEC foi encaminhada pelo Poder Executivo ao Congresso Nacional em junho de 2016, visando a instituir novo regime fiscal, cuja principal característica é o estabelecimento de limite global para despesas primárias por poder e órgãos autônomos. Para 2017, o limite corresponde à despesa primária realizada em 2016, corrigida pela inflação desse exercício. Para os anos seguintes, o teto é o limite do período anterior, acrescido da inflação nesse mesmo período. No Congresso Nacional, a proposta foi alterada em alguns dispositivos, tendo sido, contudo, preservado o espírito da matéria, que foi promulgada como Emenda Constitucional 95/2016. Proposta original disponivel em http://www.planalto.gov.br/ccivil_03/Projetos/ PEC/2016/msg329-junho2016.htm. Acesso em: 10 dez. 2016.
} 
posições coletivamente aceitas como soluções aos problemas públicos. Ao contrário, a palavra oficial é sempre objeto de lutas, inclusive por parte de agentes não-estatais (movimentos sociais, pesquisadores, mídia, entre outros). No entanto, aqui se pretende mostrar como os agentes governamentais criam uma espécie de drama em que se representa o que é o domínio público, tornando-o visível e enunciável por meio de instrumentos e rituais que procuram converter perspectivas singulares em coletivas, empregando uma linguagem própria ao campo estatal.

No caso da PEC 241, o debate público sobre sua aprovação é realizado em meio à construção da representação que associa despesa pública à crise econômica, da qual resulta a imagem da PEC como caminho para o que se nomeia como uma reconstrução nacional. 0 artigo busca demonstrar que a legitimidade de tal perspectiva é construída com base na combinação da autoridade científıca e burocrática do pensamento econômico convencional, informando a narrativa da crise como expressão do excesso de Estado e de despesas públicas.

$\mathrm{Na}$ próxima seção, são abordados os principais conceitos utilizados por Gusfield (1984) em sua análise do discurso científico. 0 trabalho de Gusfield balizará, em seguida, o estudo da PEC 241, a ser realizado de forma a descrever os procedimentos discursivos de que se vale a palavra oficial para criar representações em torno da medida, por meio da articulação entre gasto público e crise. Preliminarmente, será mostrado como o pensamento econômico no Brasil se constitui de modo a concentrar credibilidade para ocupar posições estratégicas no campo estatal e orientar as decisões governamentais. Elas tendem a ser legitimadas na medida em que se sustentam em pressupostos cognitivos associados a uma racionalidade econômica, produzindo um estilo de decisão tecnocrático, fundado em saberes econômicos, por meio dos quais se postula falar em nome do coletivo.

Passa-se, na terceira seção, à discussão de que a fonte da eficácia simbólica das posições no espaço público é a autoridade, isto é, o reconhecimento de que o agente fala em nome do universal, e, portanto, está habilitado a empregar instrumentos de ação pública (no caso da PEC, autoridade do pensamento econômico convencional e de sua defesa da austeridade como saída da crise). As notas conclusivas apontam para a arena pública como espaço de lutas entre pontos de vista, no qual posições alternativas só podem se cristalizar mediante novas articulações entre discurso e práticas sobre o que constitui o público.

\section{As categorias da representação social e a narrativa científica}

A seção será baseada no livro The culture of public problems: $\mathrm{d}$ rinking-driving and the symbolic order (1984), de Joseph Gusfield, no qual a prática científica é apreendida como retórica voltada à construção linguística de seus objetos. 0 autor aborda o problema do uso do álcool entre motoristas nos Estados Unidos, procurando mostrar que a ciência apreende a questão como um fenômeno objetivo, apagando os pressupostos culturais que transformam dados em representações sociais e informam políticas públicas.

Gusfield focaliza os procedimentos discursivos do texto científico, mapeando o conjunto de elementos pelos quais a narrativa constitui um drama que confere significado ao fenômeno do uso do álcool por motoristas. $\mathrm{O}$ artigo analisado por Gusfield foi Identification of problem-drin- 
king among drunken drivers, de Julian A. Waller, publicado no Jornal da Associação Médica Americana, em 1967. A categoria central do artigo é a de "motoristas bêbados”, presente no título, à qual é associado um atributo: o consumo problemático de álcool. 0 título já se vale de uma operação narrativa estratégica, que consiste da identificação entre dois fenômenos: uso problemático de álcool e direção. Dessa forma, a questão é enquadrada de modo a fechar a complexidade e a incerteza em um mundo organizado de relações causais entre dois fenômenos, apagando conexões de outras naturezas. Especialmente, salienta-se o agente e seus atributos (drunker), em detrimento de uma análise situacional, cuja ênfase recairia sobre os elementos da cena (drinking).

Outro ponto a destacar é o estilo da narrativa, que inicia com uma tensão, anunciando que é crescente a proporção de motoristas que sofrem acidentes ao beber ou são presos por dirigirem bêbados e que não fazem uso social do álcool. A tensão é estruturada por duas perspectivas. De um lado, a abordagem clássica segundo a qual motoristas que bebem são representativos do universo que faz uso social da bebida. De outro, a novidade de que motoristas consomem álcool de forma problemática.

Gusfield (1984) chama atenção para o arranjo lógico que estrutura o artigo. As consequências em termos de políticas (o que deve ser feito) são lidas como resultado dos procedimentos científicos utilizados e dos dados obtidos. A clivagem "bebedores sociais $\mathrm{x}$ bebedores que fazem uso problemático do álcool" se resolve com uma mudança de perspectiva em direção à imagem do bebedor problemático. A legitimidade da nova perspectiva é lastreada na externalidade de dados (“correlações encontradas dão conta de que
...") e no método adotado. No seu postulado de cientificidade, o texto busca conferir ao leitor as condições para apreender as propriedades "reais" do objeto. Simultaneamente, o autor expressa suas credenciais científicas e se vale de estilo no qual o fenômeno aparece como algo sobre o qual ele não projeta qualquer subjetividade. Para tanto, emprega a linguagem passiva, sendo frequentes expressões como "decidiu-se usar o método" e "os testes indicam correlação entre fenômenos” (WALLER, 1967 apud GUSFIELD, 1984).

0 estilo passivo é fundamental para persuadir a audiência acerca das propriedades do fenômeno, apresentado como algo independente da linguagem científica. Cientista e audiência observam metodicamente os fatos, não integrando o grupo social tomado como objeto de pesquisa. Consequentemente, a linguagem não pode ser emotiva ou sentimental, a não ser ao fim, em que o autor, dirigindo-se aos decisores governamentais, procura persuadi-los em relação às ações a serem adotadas. 0 leitor não se identifica com as categorias que estruturam o texto em razão de seu apelo emotivo, mas por serem representadas, não apenas no sentido mental, mas também teatral, como um objeto (drunker driver) que porta atributos (problem drinking) (GOFFMAN, 2005).

À retórica do método se soma a retórica da substância, que consiste na representação propriamente dita do fenômeno. A figura do bêbado (drunker) em contraposição ao bebedor (drinker) é uma imagem visual que converge para a experiência do senso comum e para a imaginação da audiência, construindo familiaridade, nos termos de Moscovici (2012). 0 termo transmite atributos negativos de uma pessoa, criando a atmosfera necessária à conversão da perspectiva em problema público, sustentada pela defınição socialmente compartilhada (ainda 
que de forma tácita) do comportamento incompativel com a ordem simbólica.

0 artigo se refere aos motoristas embriagados, mas estuda pessoas presas por violarem a lei ao dirigirem sob a influência do álcool, o que é atestado por determinado nível de álcool no sangue. No entanto, prisões com ou sem acidente não são evidência de embriaguez na concepção legal ou do senso comum. A narrativa envolve a conversão do "fato" numa imagem (drunken driver). Ao fato, é acrescido algo que lhe confere sentidos, criando uma identidade, representada sob a forma de pares antitéticos: motoristas bêbados (patológicos) $\mathrm{x}$ motoristas não-bêbados, assim como há motoristas jovens e idosos.

Gusfield (1984) conceitua metáforas como expressões que estendem o uso do dado primário, imprimindo-lhe sentidos próprios. Elas correspondem a representações dos dados que criam associações àquilo que é conhecido e familiar à audiência. A significação é estruturada de modo a converter dados em categorias gerais, que podem ser lidas como arquétipos conceituais: drinking drivers $x$ nondrinking drivers; social drinkers $x$ problem drinkers. A tipologia confere um nome e atribui características específicas ao fenômeno, sustentando-se em estatísticas de prisões entre motoristas bêbados, de forma a transformar os bebedores-problema em desviantes.

0 motorista que bebe passa a ser visto como um paciente, e não como um delinquente. Gusfield (1984) afirma que o autor desloca a cena do tribunal para a clínica. Redistribui-se, portanto, o poder de lidar com a questão, que passa dos advogados, juízes e policiais aos profissionais de saúde. Além disso, o artigo comentado por Gusfield (WALLER, 1967 apud GUSFIELD, 1984) posiciona o motorista que bebe na hierarquia da estrutura social americana. Valendo-se de cruzamentos estatísticos, localizará os bebedores-problema nos níveis de renda e status mais baixos. Dessa maneira, proposições de fato são convertidas em proposições de políticas. Dados primários são classificados em categorias gerais, por meio de atos de seleção que equivalem à representação artística. A narrativa produz performaticamente imagens e categorias de percepção, legítimas apenas na medida em que se valem da linguagem da ciência.

A abordagem de Gusfield (1984) investiga como se dá a construção social dos problemas coletivos, mostrando que eles não são expressão de métodos axiologicamente neutros de apreensão da realidade. Em particular, ela informa a análise de como a prática científica constrói sentidos, em meio a um processo de definição de categorias cognitivas e morais que criam os problemas públicos. É esse aspecto que servirá de base ao presente trabalho, que visa a investigar como os agentes oficiais, valendo-se da autoridade do pensamento econômico convencional, criam associações entre crise econômica e regime fiscal para definir a despesa pública como problema coletivo.

A perspectiva que se debruça sobre a construção de uma cultura dos problemas públicos é produtiva para avançar nos estudos acerca das conexões entre as dimensões econômica, social e simbólica dos atos de Estado. Esta abordagem se soma a um conjunto de autores que reposicionam a economia em suas interações com os meios políticos, linguísticos e institucionais, procurando explicar formações históricas específicas.

Boschi e Gaitan (2008) assinalam que não há uma modalidade fixa de Estado capitalista, devendo-se apreender as insti- 
tuições estatais como aspectos constitutivos dos regimes produtivos. Fatores como a capacidade do sistema político enfrentar situações de conflito e canalizar demandas são centrais na explicação das trajetórias de desenvolvimento dos países.

Por seu turno, Grün (2013) examina os termos em que se dá legitimidade simbólica da ortodoxia econômica no Brasil, em meio a um regime de dominação financeira, sustentado pela esfera cultural. É nela que se produz um conjunto de assimetrias econômicas em favor dos interesses financeiros (especialmente, em termos de nomear as razões da crise e indicar as saídas a ela), de modo que não é a riqueza que produz legitimidade, mas o inverso, tendo em vista o controle pela ortodoxia das categorias cognitivas a partir das quais a crise é interpretada.

Nesse contexto, pode-se apreender o papel do Estado na trajetória de cada país. Em particular, mostra-se em que termos se dão as alianças entre autoridade burocrática e científica, fazendo com que o pensamento econômico convencional acumule credibilidade para construir os instrumentos de ação pública concebidos como soluções a problemas coletivos como o desemprego.

No entanto, é necessário complementar essas perspectivas e investigar a forma como os agentes investem concretamente no jogo de constituição de sentidos. Seu alvo é a construção de categorias cognitivas e morais por meio das quais se apreende o que é o domínio público. Sob essa chave, procura-se mostrar como os problemas coletivos são simbolicamente construídos, através de um trabalho pelo qual se atribui forma oficial a posições de valor, transfigurando-as em definições que tendem a ser aplicadas à realidade social e a definir uma imagem do comportamento compatível com a ordem pública.
É nesse sentido que a abordagem de Gusfield (1984), apoiada em outros autores, que serão mobilizados ao longo do trabalho, permite entender a ordem pública em sua dimensão cultural, jogando luz sobre como os agentes criam o público como uma ficção, valendo-se de instrumentos linguísticos pelos quais se engajam na construção performática dos problemas coletivos. Esse aspecto será central na análise da PEC 241 e dos procedimentos discursivos que cristalizam a ideia de despesa pública como obstáculo para o desenvolvimento do Brasil.

\section{PEC 241: a arte da representação e o mito do caminho único}

Após o impeachment de Dilma Rousseff, o novo governo assumiu sob a retórica das reformas necessárias para retomar o rumo do desenvolvimento e "colocar o Brasil nos trilhos", como se o país estivesse desgovernado. Entre outras reformas propostas, destaca-se a revisão do modelo fiscal. 0 governo que assumiu o país, após o impeachment, associa a crise econômica brasileira a uma indisciplina fiscal durante os mandatos do Partido dos Trabalhadores (2003-2016), indicando como parte da solução a Proposta de Emenda à Constituição que impõe teto às despesas primárias (PEC 241).

0 objeto da seção é reconstruir a narrativa governamental em torno da PEC 241, por meio da qual são construídas representações e sentidos sobre a crise brasileira. Serão focalizados o estilo, os procedimentos e as categorias de que se vale a retórica oficial, constituindo a narrativa da PEC como um drama que enquadra a questão de tal modo que ela seja representada como ação inexorável para a realização do interesse nacional.

Vale ressaltar que o foco do trabalho não é a recepção da medida pela popula- 
ção, tampouco o aprofundamento dos termos em que a luta pelo controle de sentidos em torno da PEC ocorre. Conforme já assinalado, o trabalho se detém sobre a narrativa oficial, procurando evidenciar o papel dos agentes governamentais em criar definições sobre o interesse coletivo, com base em linguagens e instrumentos que sustentam visões sobre as práticas legítimas no espaço público.

0 discurso oficial se constrói por meio do controle de instrumentos e recursos que conferem autoridade ao agente do campo estatal para falar em nome do coletivo, sob a forma de uma lógica burocrática e de aparência racional (BOURDIEU, 2014). Por outro lado, é preciso entender como linguagens específicas (particularmente, a do pensamento econômico convencional) são investidas do poder de constituir o interesse geral e definir as práticas socialmente autorizadas, sobretudo enquanto soluções à crise. Para tanto, antes de iniciar a análise do discurso oficial em torno da PEC, é necessário entender alguns aspectos do pensamento econômico tradicional e como ele incide sobre o discurso e as decisões produzidas no campo estatal.

\subsection{A formação do pensamento econômi- co no Brasil}

É longa a história da presença de agentes com formação econômica em posições centrais do Estado brasileiro. Pode-se estudar como eles compõem as elites dirigentes do país, tendo papel ativo nas decisões governamentais em diferentes períodos. Segundo Loureiro (2006), o papel crescente dos economistas se deu em meio à formação do Es- tado desenvolvimentista, a partir de Vargas, e às lutas políticas e ideológicas daí resultantes. Vale citar como exemplos de instâncias, desde as quais esses agentes participavam das decisões públicas os conselhos técnicos no governo Vargas, os grupos executivos no governo Kubitscheck, o Banco Nacional de Desenvolvimento Econômico e a Superintendência da Moeda e do Crédito.

Por um longo período, as verdadeiras escolas de economia foram as agências de formulação da política econômica, instituições de pesquisa aplicada (como o Instituto Brasileiro de Economia da Fundação Getúlio Vargas - IBRE, criado em 1951) e organismos internacionais (a exemplo da Comissão Econômica para América Latina e o Caribe - CEPAL), tendo em vista a debilidade acadêmica da ciência econômica no Brasil. A situação começa a se alterar em 1945, com a fundação das primeiras escolas de economia, mas só a partir da década de 1970 se inicia a consolidação da formação universitária da Economia, por exemplo com a criação de programas de pós-graduação e de revistas especializadas, além da ida de brasileiros para frequentar programas de doutorado no exterior e da chegada de docentes estrangeiros para lecionar no Brasil. Todas essas medidas, que aproximaram a ciência econômica brasileira dos padrões dos países desenvolvidos (em especial, da academia americana), reforçaram o papel da formação econômica como pré-requisito para a ocupação de postos técnicos e políticos estratégicos (LOUREIRO; LIMA, 1994).

A maneira como as diferentes escolas respondem ao processo de internacionalização revela a polarização entre ortodoxos e heterodoxos ${ }^{2}$. Desde a sua constituição, o

2. Loureiro e Lima (1994) mostram que as escolas de economia associadas a um pensamento político de esquerda eram mais resistentes ao processo de americanização. 
campo do pensamento econômico se organiza sob a forma de conflitos entre adeptos de uma maior intervenção estatal (heterodoxos) e aqueles mais inclinados à atuação livre do mercado (ortodoxos). A competição em torno das decisões econômicas já aparece na década de 1940, por meio da famosa disputa entre Roberto Simonsen e Eugênio Gudin, no âmbito do Conselho Nacional de Políticas Industriais e Comerciais, órgão consultivo vinculado ao Ministério do Trabalho, Indústria e Comércio. Enquanto Simonsen advogava pelo planejamento estatal e pela proteção à indústria nacional, Gudin era crítico à intervenção do Estado na economia.

As disputas não se circunscrevem a diferenças em termos de pensamento econômico, remetendo a relações dos agentes com frações do capital. Simonsen era um industrial, fundador do Centro das Indústrias do Estado de São Paulo, instituição precursora da FIESP (Federação das Indústrias do Estado de São Paulo), enquanto Gudin trabalhou em diversas empresas e estabeleceu relações com o capital estrangeiro. Por outro lado, é preciso situar a luta de ideias na dinâmica do próprio campo do pensamento econômico como espaço relativamente autônomo, examinando como os agentes concorrem pelo acesso a recursos materiais e simbólicos (isto é, por acumular crédito social para veicular a linguagem econômica), vinculados a espaços de governo, mercado, academia, mídia e organizações multilaterais. A luta se intensifica diante da crescente ocupação de postos de prestígio pelos representantes do pensamento econômico no setor público entre 1930 e 1964, tendo em vista a centralidade atribuída às questões econômicas nos objetivos governamentais.

No regime militar, manteve-se a tendência de participação de economistas em posições governamentais estratégicas. 0 fato revela uma associação entre condições autoritárias e busca por resultados econômicos como fator de legitimação do regime. No entanto, mesmo com a redemocratização, as instâncias de decisão econômica seguiram fechadas ao controle democrático. Um dos legados para o funcionamento do Estado dos 21 anos de ditadura militar foi a consolidação do estilo tecnocrático de gestão pública e, especialmente, da economia (DINIZ, 2001) ${ }^{3}$.

Em circunstâncias de maior ou menor intervencionismo econômico, consagrouse a ideia de que o capital simbólico dos economistas os autoriza a concentrar poderes decisórios, lastreados em uma racionalidade econômica que, no limite, prescindiria da validação dos mecanismos

3. É ilustrativo que as reformas administrativas mais relevantes no Brasil tenham sido realizadas em condições autoritárias. Primeiro, a reforma de Vargas, procurando instituir uma burocracia racional-legal, cujo símbolo é o Departamento Administrativo do Serviço Público - DASP. Depois, no período militar, o Decreto-Lei 200, que buscava modernizar a administração pública e lhe conferir maior flexibilidade. Ademais, outros traços reforçam a tensão entre democracia e funcionamento do Estado no Brasil, resultando em centros decisórios insulados do sistema político, social e eleitoral. Por exemplo, a criação de instâncias paralelas para realizar objetivos estatais funcionando como ilhas de excelência, blindadas em relação às redes clientelistas (como os grupos executivos no governo de Juscelino). Além disso, pode-se citar as tentativas de constituir cadeias de decisões econômicas centralizadas, que superassem a fragmentação da máquina pública e a sua captura por interesses diversos, garantindo um controle estrito sobre a formulação e a implementação de políticas econômicas pela tecnocracia, como o Conselho de Desenvolvimento Econômico, no governo Geisel (CODATO, 1997). 
democráticos. Consequentemente, posições específicas do campo burocrático passam a ser representadas como instâncias monopolizadas pelos que detêm competência técnica, em virtude da qual elas se mantêm relativamente distantes das demandas sociais e políticas por acesso aos recursos públicos. É o caso, em particular, da política fiscal, que se passa a abordar.

\subsection{Estado da arte do debate sobre política fiscal no Brasil}

0 conflito entre posições teóricas intervencionistas e liberais se transfigura, no caso da política fiscal, para o papel desempenhado pelas despesas públicas, especialmente em momentos de crise econômica. Esquematicamente, pode-se dizer que há, de um lado, os que consideram que a política fiscal deva ser utilizada para indicar ao mercado que não há risco de default. Uma política fiscal que sinalize compromisso com a sustentabilidade da dívida pública produz confiança dos agentes econômicos, repercutindo sobre investimentos e a renda. De forma oposta, ampliações de gasto tendem a incidir negativamente sobre a atividade econômica. Sob essa chave, Barbosa Filho (2017) atribui a crise econômica iniciada no governo Dilma a um conjunto de choques de oferta e demanda, com destaque para os estímulos fiscais que teriam ampliado o déficit e a dívida pública, impactando o risco país e a taxa de juros.

De outro lado, há o pensamento econômico vinculado à tradição heterodoxa, segundo o qual a despesa pública pode produzir efeitos sobre a demanda agregada, induzindo o investimento privado. Havendo capacidade ociosa na economia, a demanda estimula o aumento da atividade econômica. Nesse sentido, o gasto público seria central para mudar o ambiente recessivo. A contração fiscal pioraria as expectativas dos investidores privados, reforçando a queda da atividade econômica e das receitas.

Em relação ao período 2011-2014 (primeiro governo Dilma), Dweck e Teixeria (2017) salientam que a despesa primária apresentou baixa taxa de crescimento, próxima à do segundo mandato de FHC. No entanto, a relação despesa/PIB se acelera, diante do baixo crescimento do denominador, o que, inclusive, impacta a receita, gerando resultados primários menores. Os autores alegam que a subida da dívida pública se deu, principalmente, em razão do pagamento de juros e da queda real do PIB, e não da piora do resultado primário, de modo que não seria válida a "tese da gastança" como razão da crise. Os défıcits fiscais colhidos a partir de 2014 se deveriam, sobretudo, à queda da receita. A principal mudança no governo Dilma não teria sido sua disposição para ampliar gastos, mas uma alteração na composição das despesas, em favor de investimentos com menores efeitos multiplicadores e subsídios. Desse modo, os resultados primários menores não teriam sido eficazes em sustentar o crescimento.

Outros autores, como Serrano e Summa (2015), não apenas descartam a ideia de que a crise se deve ao crescimento das despesas públicas, como afırmam que a desaceleração econômica desde 2011 é explicada por políticas monetárias e fiscais contracionistas, sucedidas da tentativa de ampliação dos investimentos privados, via subsídios e desonerações, que só fizeram ampliar a margem de luro das empresas. Em 2015, a aposta teria sido dobrada, com redução dos gastos e do crédito, aumento de impostos e das taxas de juros. A justificativa residiria na tentativa de ampliar a confiança dos investidores e evitar que o Brasil perdesse 
o grau de investimento junto aos credores internacionais.

$\mathrm{Na}$ perspectiva heterodoxa, a elevação da despesa primária deixa de ser o fator explicativo da recessão. Os resultados primários negativos não são tomados como razão da crise, a queda das receitas deve ser levada em conta para avaliar o desempenho da política fiscal e o aumento da dívida não pode ser observado apenas como consequência das despesas primárias. É preciso questionar o caráter pró-cíclico da regra fiscal de resultados primários anuais, em que uma queda da receita se combina a despesas rígidas (obrigatórias), gerando resultados primários menores em razão da queda da atividade. Como a meta fiscal só pode ser alterada por lei, dificulta-se o uso da política fiscal como instrumento anticíclico, voltado a estimular despesas relevantes para reaquecer a economia ${ }^{4}$.

Sob essa chave, os gastos não deveriam ser pensados apenas no curto prazo, gerando-se uma visão restritiva, que converte em objetivo unilateral da política fiscal o ajuste das despesas à queda das receitas. A política fiscal poderia ser orientada por outras regras, buscando sustentabilidade em um prazo mais longo, de forma a flexibilizar a gestão fiscal e a viabilizar despesas com maiores efeitos multiplicadores e essenciais à continuidade dos serviços públicos, sobretudo em circunstâncias de crise. No entanto, um arranjo institucional em que a despesa pública não seja apenas uma variável de ajuste às condições da economia requer que ela seja representada como uma solução a problemas coletivos, tanto a partir de categorias conceituais expostas pelos agentes especializados, como na percepção sobre seus efeitos pela população, fortemente dependente da mídia.

Nesse sentido, procura-se mostrar que as escolhas de política econômica são também orientadas por uma dimensão simbólica. A questão fiscal não se exaure na existência de modelos teóricos distintos, mas envolve o crédito que dispõe a ortodoxia para nomear os problemas coletivos, definindo a despesa pública em oposição ao interesse universal, de modo que o cumprimento da meta fiscal anual tenderá a ser representado como expressão do interesse público e de uma gestão pública eficiente. Nesse contexto, reduzir as despesas, sobretudo diante da queda das receitas, passa a ser uma espécie de índice absoluto de bem-estar, criando-se uma ordem simbólica na qual o comportamento publicamente aceitável é achatado na austeridade.

Para entender como se dá a construção dessa ordem simbólica, é preciso explicar como os agentes atribuem sentido à crise como um problema público, mas também como utilizam seu "capital de palavras" para indicar as saídas da crise, articulando recuperação da ordem à austeridade (BOURDIEU, 2014). Diante dessa opera-

4. 0 caráter pró-cíclico do resultado primário foi relativizado pela vigência de algumas regras fiscais. Em particular, entre 2005 e 2015, a lei de diretrizes orçamentárias previu possibilidade de abatimento da meta de despesas com investimentos prioritários (Projeto Piloto de Investimentos - PPI, e Programa de Aceleração do Crescimento - PAC). A partir do exercício de 2016, tal possibilidade foi retirada da lei, o que sinaliza para o reforço do discurso da prudência fiscal como solução para a crise ainda no governo Dilma. 5. ZITTOUN (2014) afırma que atribuir causa a um problema é uma operação de substituição de um fenômeno por outro que deve ser entendida como um jogo de linguagem pelo qual se transforma um problema geral (crise) em algo tratável (regime fiscal). 
ção linguística que converte prosperidade econômica em controle fiscal ${ }^{5}$, constrói-se uma narrativa na qual a contenção da despesa pública encarna o sentido do interesse universal, convertendo-se na proposição de novo regime fiscal, representado como prática socialmente autorizada para reconduzir o país à ordem. Nesse contexto, as despesas públicas passam a se submeter a um limite anual, sendo congeladas em termos reais por um período de até vinte anos.

\subsection{As categorias de representação social da PEC 241}

Para empreender uma análise de como a proposta de congelamento real dos gastos é realizada como um drama em que se cria uma representação da ordem pública, foram selecionados três textos sobre a questão: apresentação do Ministério da Fazenda ${ }^{6}$; relatório aprovado no plenário da Câmara dos Deputados, favorável à aprovação da $\mathrm{PEC}^{7}$; e a Exposição de Motivos da $\mathrm{PEC}^{8}$, encaminhada pelo Poder Executivo ao Congresso Nacional. Com base neles, pretende-se mostrar como os agentes governamentais põem o discurso "em movimento", valendo-se do controle da palavra oficial para conectar problema (crise) e solução (contenção das despesas). Mas também se verificará que sua construção se apoia na autoridade do argumento econô- mico ortodoxo, que incide sobre a palavra oficial, combinando austeridade e interesse público.

Primeiro, interessa mencionar como se situa o Ministro da Fazenda, Henrique Meirelles, no campo econômico e burocrático. Ele é um executivo da área financeira, tendo sido presidente do BankBoston e ex-presidente do Banco Central no governo Lula. Suas decisões, usualmente relacionadas à austeridade, costumam ser justificadas pelo resgate da credibilidade da política econômica frente ao mercado. A posição de Henrique Meirelles no espaço estatal ilustra os laços entre finanças, gestão pública e controle dos sentidos atribuíveis ao interesse comum. Se a ideia de recuperação da ordem envolve uma gestão fiscal que reconstrua a credibilidade do país, essa credibilidade é encarnada na figura que não apenas detém a linguagem dos instrumentos econômicos convencionais, como é recrutado junto às fileiras do mercado para que possa ser investido da autoridade de realização do interesse público, representado como controle fiscal ${ }^{9}$.

Analisando a apresentação do ministro, vale notar como são ordenados os elementos da narrativa. Ela começa por apresentar o novo regime fiscal, passando à dimensão da crise econômica, para, em seguida, atribuir-lhe causas, articuladas ao abandono da prudência fiscal. Diante da constru-

6. Disponivel em: <http://www.fazenda.gov.br/centrais-de-conteudos/apresentacoes/2016/2016-08-24apresentacao-pec-241-2016-ministro>. Acesso em: $10 \mathrm{dez} .2016$.

7. Disponivel em: <http://www.camara.gov.br/proposicoesWeb fichadetramitacao?idProposicao=2088351>. Acesso em: 10 dez. 2016.

8. Disponivel em: <http://www.planalto.gov.br/ccivil_03/Projetos/ExpMotiv/EMI/2016/83.htm>. Acesso em: 10 dez. 2016.

9. Analogamente, em 2015, Dilma Rousseff escolheu Joaquim Levy para sinalizar ao mercado que adotaria uma política fiscal austera. Levy já havia ocupado outros postos públicos, mas sua trajetória também é associada ao Banco Bradesco. 
ção do problema, a PEC 241 é posicionada como parte da resposta estrutural à crise, expondo um conjunto de números que demonstrariam que o nível da despesa se mantém acima do que seria aceitável.

0 argumento do ministro é constituído como uma espécie de filme hollywoodiano (BORDWELL, 2004). Coloca-se um problema (uma tensão sob a forma da apresentação da intensidade da crise e dos diferenciais de crescimento entre despesa e receita) e se estabelecem os meios de resolvê-lo, em meio a circunstâncias impeditivas ${ }^{10}$. Tudo caminha para o desfecho dramático no qual os obstáculos são enfrentados, de modo a se alcançar os objetivos. 0 obstáculo é o regime fiscal do país; o objetivo é estabilizar o gasto, que recepciona toda a carga negativa enquanto razão da crise.

No entanto, o caminho até o desfecho não é pavimentado apenas pelo estilo emotivo de construção do problema. Na retórica em favor da PEC, há uma combinação do estilo emotivo com argumentos técnicos e estatísticos que constroem o problema como uma realidade externa ao autor e aos receptores do discurso. Em relação ao tom emotivo, a exposição do ministro se vale de linguagem dramática para representar a crise e seus efeitos: "sem precedentes", "pessoas não vão melhorar de vida de forma defınitiva”, "Brasil não será um país desenvolvido e justo".

Logo a seguir, são apresentadas as ações para a saída da crise. Na medida em que elas são nomeadas como condições, a narrativa transforma a ação em imperativo, dever-ser em ser, convertendo-a em "necessidade objetiva” e, portanto, buscando autorizar-se diante do público na medida em que nega sua natureza de escolha política. Para tanto, numa espécie de organização lógica de um modelo estruturado, em que causas vão se desdobrando em consequências e ações, o conjunto de dados apresentados culmina, como que naturalmente, na PEC 241. A medida é conceituada, nos termos da apresentação, como estratégia que visa a recobrar o equilíbrio fiscal com visão de longo prazo e criar regras que contenham a pressão por expansão do gasto além da capacidade de pagamento do governo.

Após uma série de estatísticas sobre a crise econômica e a apresentação dos objetivos da PEC 241, são expostos dados com vistas a precisar a situação fiscal do país. 0 estilo busca construir um objeto externo ao texto, captado por meio de dados econômicos. Tal como na obra analisada por Gusfield (WALLER, 1967 apud GUSFIELD, 1984), o autor se coloca como observador passivo que se limita a reproduzir os dados que expressam um real independente da narrativa. Entretanto, não postula apenas uma autoridade cientifica (que se apresenta sob a forma de conhecimento econômico para interpretar os fatos e a crise), mas, lastreado na linguagem econômica, fala em nome do interesse coletivo.

Nesse sentido, procurará fazer crer que agir como representante do interesse pú-

10. Deleuze se refere à narração associada ao cinema clássico como um espaço que se define por um campo de forças, oposições e tensões entre essas forças, que se resolvem de acordo com a distribuição de objetivos, obstáculos, meios e desvios. As tensões se dissipam por meio de leis de mínimo e máximo, por exemplo, o caminho mais simples, a palavra mais eficaz, o mínimo de meio para um máximo de efeito (DELEUZE, 2005). Será mostrado que a narrativa oficial se aproxima da estrutura narrativa cinematográfica de que fala Deleuze, estabelecendo-se a correlação entre as séries relativas à política fiscal e à narrativa do cinema clássico. 
blico implica garantir as condições para que o país volte a ter credibilidade junto ao setor privado, responsável pelos investimentos e pela geração de empregos. Em outros termos, faz a linguagem econômica convencional ocupar o vazio do interesse público, dotando-o de contornos precisos. Os dados econômicos mostrados expressam, em geral, a redução do nível de atividade da economia e as consequências em termos de emprego. Sua associação com a questão fiscal não é expressão da realidade apreendida empiricamente, mas um produto da construção narrativa.

A dimensão fiscal não é propriedade do nível de atividade econômica, assim como, no texto examinado por Gusfield, acidentes e uso de álcool não são associados numa realidade independente do texto (WALLER, 1967 apud GUSFIELD, 1984). 0 autor produz uma identificação entre atividade econômica e gasto público, de modo a reduzir a complexidade da primeira ao segundo. Há diversas variáveis que se relacionam com a atividade econômica. A ênfase na despesa pública é produto da intervenção do autor, resultando em um reducionismo, operação central na construção de sentido.

Despesas públicas e situação econômica são associadas como duas séries heterogêneas, articuladas por meio da solução do limite de gastos, que pertence a ambas as séries e desliza entre elas, aparecendo simultaneamente como palavra (significante) e objeto (significado) (DELEUZE, 2015). 0 controle de despesa preenche o signo vazio do interesse público, de modo a articular um discurso sobre o público (austeridade como recuperação da ordem) e os instrumentos públicos socialmente homologados (a política fiscal restritiva).

0 ponto é como se dá a produção de sentido que procura autorizar o limite de gastos, nomeando-o como instrumento público que designa a crise, assim como contém a fórmula para sua superação. A despesa pública aparece como razão da crise em função da maneira como estão dispostos os termos de cada série, articulados pela austeridade, que lhes empresta sentido e permite passar da desordem à ordem (da crise ao crescimento). Aqui se trata de regularidade entre as séries, produzindo correspondências entre elas, mas não de causalidades. No entanto, a narrativa científica possui capacidade de construir ficções, dentre as quais a conversão da associação de eventos em causalidades.

Pode-se indagar: a crise é produzida pelo excesso de despesa primária ou a piora dos índices fiscais é efeito da crise e da diminuição das receitas, relação defendida por outras frações do pensamento econômico? Partindo-se dessa última hipótese, a conexão entre as séries da economia e do gasto público seria de outra natureza, construindo-se um sentido oposto à narrativa oficial, na medida em que a manutenção de determinadas despesas públicas seria condição para resposta à crise, invertendo seu valor e posição na estrutura simbólica. As séries convergiriam para outro elemento diferenciante - o papel da despesa pública em amortecer os efeitos da crise, que redistribuiria os pontos de cada série, atribuindo-lhes novos sentidos.

Ao associar os dados sobre a atividade econômica com a situação fiscal, a narrativa produz uma identidade entre crise e elevação do gasto público que não repousa numa realidade captada cientificamente, mas em um sistema simbólico do qual a austeridade é derivada como solução. Vale reproduzir a Exposição de Motivos da PEC 241, redigida em termos tais que essa identidade é tomada como um dado, de modo que a implicação política passa a ser representada como inexorável, convertendo a PEC em uma espécie de missão salvacionista. 
Faz-se necessária mudança de rumos nas contas públicas, para que o País consiga, com a maior brevidade possível, restabelecer a confiança na sustentabilidade dos gastos e da dívida pública. É importante destacar que, dado o quadro de agudo desequilíbrio fiscal que se desenvolveu nos últimos anos, esse instrumento é essencial para recolocar a economia em trajetória de crescimento, com geração de renda e empregos. Corrigir o desequilíbrio das contas públicas é condição necessária para retirar a economia brasileira da situação crítica que Vossa Excelência recebeu ao assumir a Presidência da República (BRASIL, 2016).

A narrativa representa um drama que transforma fato em imaginação. Ao estabelecer relações entre crise e gasto, a palavra oficial não está apenas descrevendo um fenômeno, mas fabricando uma representação social, pela qual ideia e imagem se associam (MOSCOVICI, 2012). Metáforas são transferências de um sistema aplicadas a outro. Ao sistema primário (atividade econômica) são acrescidos ou eliminados determinados aspectos (regime fiscal). Neste último caso, por exemplo, as receitas são desconsideradas. Há uma breve referência a elas pelo Ministro da Fazenda, que as expõe de forma sumária como suficientemente elevadas para que seja possível ampliá-las, visando ao reequilíbrio das contas. Não se questiona para quem são elevadas ou, de outro modo, se há espaço para alguma tributação, por exemplo, de dividendos distribuídos a pessoas físicas. No âmbito da OCDE (Organização para a Cooperação e Desenvolvimento Econômico), apenas a Estônia adota um sistema como o brasileiro, de isenção total de tributação desse tipo de renda (GOBETTI; ORAIR, 2016) ${ }^{11}$.

Caso a questão fosse apreendida desde o ponto de vista das receitas, o enquadramento ficaria mais próximo de uma abordagem situacional. A piora das contas públicas seria efeito da queda conjuntural das receitas, mais do que da elevação dos gastos. Os déficits públicos primários, produzidos apenas em dois anos, entre os treze completos dos governos petistas, seriam consequência da crise, e não sua causa. 0 gasto público não seria representado em termos de atributo estigmatizante na lida com a coisa pública (a metáfora da "gastança" como razão da crise), mas enquadrado em meio a circunstâncias nas quais a crise não mais apresentaria uma relação linear com a despesa pública ${ }^{12}$.

0 enquadramento conferido à questão implica a limitação das despesas primárias, sem se referir às despesas financeiras (como as voltadas ao pagamento de juros), tomando-as simplesmente como expressão do nível de endividamento público ${ }^{13}$. 0 que se deseja frisar é que a relação entre des-

11. Barbosa (2017) defende o argumento de que o equilíbrio fiscal também requer recuperação da receita tributária do governo. Para tanto, elenca uma série de possibilidades, dentre as quais um ajuste da tabela do imposto de renda sobre pessoas físicas, a criação de um imposto federal progressivo sobre grandes heranças e a elevação da tributação direta na fonte sobre rendimentos financeiros de pessoas e empresas.

12. Nessa hipótese, ainda que se reconhecesse a necessidade de um ajuste fiscal como resposta à crise, a despesa pública não seria encarada como único caminho para obtê-lo, tampouco a crise seria interpretada a partir de uma oposição inequívoca entre despesa pública e interesse comum.

13. Parcela expressiva do crescimento da dívida pública nos últimos anos é devida ao crescimento dos juros. Enquanto economistas ortodoxos destacarão que os juros altos são função da política fiscal expansionista, autores de outras correntes defenderão, por exemplo, que resultados primários positivos podem não levar à redução das taxas de juros (GOBETTI e AMADO, 2011). 
pesa primária e crise não é expressão de uma realidade dada, captada por modelos econômicos, mas constitui um recorte de dados, dispostos de modo a produzir "evidências" no interior de um esquema interpretativo. 0 modelo envolve a atribuição de uma relação causal, na qual a despesa pública é a razão para a crise econômica. 0 corolário é situar o país diante da opção dual entre limitar gastos pelas próximas décadas ou afundar-se na crise.

A narrativa oficial ganha tons emotivos, atribuindo à austeridade a missão de salvar o país. 0 enquadramento conceitual da questão exclui outras perspectivas, desclassificando-as enquanto soluções coerentes com o interesse coletivo. Nos termos do relatório que sugere aprovação da matéria na Câmara dos Deputados, “caso nada seja feito, o Dia do Juizo Fiscal chegará e atingirá a todos: famílias, aposentados, funcionários públicos e empresários (BRASIL, 2016, p. 24)”.

Se, no artigo estudado por Gusfield, o uso do álcool é apreendido sob a forma do bebedor social (normal) x bebedor-problema (desviante), aqui o sistema simbólico se institui em torno da associação das categorias gasto-crise e das oposições imprudência fiscal $x$ crescimento econômico e Estado (extrator de recursos da sociedade) $\mathrm{x}$ mercado (gerador de renda que depende da credibilidade transmitida pelo Estado). A imprudência fiscal, atributo que confere essência identitária às decisões que implicam expansão de despesas públicas, faz-se crível por meio do efeito de familiaridade pelo qual a audiência tende a reconhecer o sentido a ela atribuído na narrativa da PEC. Em cadeia nacional, o Ministro da Fazenda se dirigiu à Nação nos seguintes termos: "na sua casa, todos sabem que não podem se endividar para gastar mais do que ganham, continuamente. Com o governo acontece a mesma coisa ${ }^{14 "}$. Nesse sentido, a argumentação se constrói por analogia com a economia doméstica, convertendo matéria esotérica em definições cristalizadas no senso comum.

Os que mais sentem os efeitos da crise (desempregados) tendem a retomar a autoimagem difundida na sociedade brasileira de um Estado patrimonialista que não se submete ao padrão moderno da impessoalidade e ao império da lei. Do Estado patrimonialista ao Estado que se endivida excessivamente com despesas decorrentes das relações de favorecimento (cuja prova tende a ser percebida pelo sujeito desempregado como sendo a sua própria situação de precariedade, na medida em que ele se sentirá preterido pelo Estado, e não pelo mercado virtuoso) é um passo pequeno, sobretudo se a oratória oficial reforça as representações negativas do Estado ${ }^{15}$.

Tais representações subentendem uma sociedade cujo recurso central para explicar

14. Parcela expressiva do crescimento da divida pública nos últimos anos é devida ao crescimento dos juros. Enquanto economistas ortodoxos destacarão que os juros altos são função da política fiscal expansionista, autores de outras correntes defenderão, por exemplo, que resultados primários positivos podem não levar à redução das taxas de juros (GOBETTI e AMADO, 2011).

15. Não há como desenvolver o assunto nos limites do artigo, mas vale assinalar que a imagem de um país cuja singularidade cultural residiria na força das relações pessoais ganha sistematização teórica na obra de um autor como Holanda (2003). Ele assinala a centralidade da família em nossa sociedade (e, portanto, dos círculos pessoais), que seria o modelo de prática social, mesmo nos casos em que deveria viger um comportamento regido por normas objetivas e abstratas, como nos atos de Estado (HOLANDA, 2003). 
as desigualdades seria o acesso a privilégios sustentados por negócios públicos, em oposição a sociedades desenvolvidas, idealizadas como moralmente superiores e baseadas na falsa imagem da competição social igualitária (SOUZA, 2015). Limitar gastos é “naturalmente" positivo caso se pense no Estado como uma máquina que subtrai recursos da sociedade de forma ineficiente, mantendo privilégios em detrimento do desenvolvimento de uma ordem privada igualitária.

A categoria do Estado como negatividade é um tipo social, uma forma de cognição da realidade que pode produzir reconhecimento junto à audiência, na medida em que estigmatiza a ampliação do gasto público, enquadrada como ilustração do descaso histórico dos agentes públicos em relação às necessidades da população (inchaço da máquina pública, subsídios, gastos ineficientes e corrupção). Mesmo sem uma discussão sobre a natureza e o impacto de cada despesa que sofreu ampliação nos últimos anos, o gasto público, citado como elemento objetivo e empiricamente apreendido, converte-se numa imagem que envolve o desperdício e o excesso praticados por gestores públicos descolados do interesse da população.
No caso examinado por Gusfield, a categoria problem drinker (como representação de drinking driver) leva à estigmatização, pois aqueles classificados por meio dela passam a ser representados por meio de uma imagem viva, compartilhada socialmente. Analogamente, a associação gasto-crise cria uma percepção negativa dos gastos, radicada numa representação de Estado, atribuindo identidade à ampliação da despesa pública. Essa passa a ser lida como fundamento da desorganização social e econômica, impactando o bem-estar dos indivíduos ${ }^{16}$.

Parte substantiva da elevação das despesas primárias nos governos anteriores foi dirigida às políticas sociais, como as transferências diretas de renda às famílias e educação ${ }^{17}$. No entanto, diante do esquema interpretativo pelo qual se lê a PEC 241 como parte da saída da crise, o gasto público não será representado pelos efeitos positivos em áreas específicas, que resultaria numa abordagem, no limite, voltada ao papel de cada despesa para a preservação do bem-estar econômico e social. 0 dado que demonstra a ampliação do gasto público é classificado de modo tal que o texto só se refere a ele no singular, dotado de sentido

16. Aqui vale fazer referência à campanha publicitária lançada pelo governo federal, cujo título é "vamos tirar o Brasil do vermelho para voltar a crescer". Em seu nível mais superficial, o sentido reforça a associação gasto-crise. Sair da crise é sair do vermelho. No entanto, valendo-se de Zizek (2006), que utiliza os conceitos de Lacan, cabe distinguir o ideal do eu (o domínio público da lei simbólica, o que o grande outro espera que façamos em público) e o supereu (a imaginação e as fantasias inassimiláveis pela moralidade pública). Para se entregar a suas fantasias, é preciso render homenagens ao oficial, ao público, ter uma versão menos incriminatória dos fatos. No caso em análise, conforme exposto, "sair do vermelho" envolve a moralidade pública concebida como botar as contas em ordem. No entanto, o discurso alinhado à lei pública tem como suplemento obsceno a própria fantasia do extermínio do outro, em que "tirar o Brasil do vermelho" envolve livrar-se do Partido dos Trabalhadores, cujos governos seriam os responsáveis pela crise econômica.

17. Para maiores detalhes, ver Pires (2016). Disponivel em: <http://fazenda.gov.br/centrais-de-conteudos/ apresentacoes/2016/2016-05-10_relatorio-de-analise-dos-gastos_site.pdf>. Acesso em: 10 dez. 2016. 
em si próprio, categorizado como explicação da crise econômica, de forma a criar links com algo conhecido no tecido social (o Estado conceituado como excesso).

Não se dirá que foram expandidos, por exemplo, os recursos com educação em relação ao PIB nos governos anteriores ${ }^{18}$, mas que o gasto público foi ampliado para além do aceitável. "Como na sua casa", este é um fator que leva à crise. Estende-se o dado da despesa pública a um imaginário em torno dela, formando-se uma associação que tende a se cristalizar entre gasto e crise. Tecendose uma analogia com o caso estudado por Gusfield (1984), pode-se falar do "Estado problema”. 0 relatório da Comissão Especial da Câmara dedicado à análise da PEC arremata a categorização do Estado, atribuindo, em tom francamente emocional, a crise e o desemprego à elevação dos gastos.

A péssima gestão, o descontrole do gasto público e o aumento insaciável da carga tributária destruíram a confiança dos mercados, azedaram as expectativas dos empresários e, consequentemente, geraram esses índices trágicos e devastadores de desemprego e recessão. Oficialmente, segundo os dados que o IBGE acaba de divulgar, já são 12 milhões de brasileiros e brasileiras desempregados, sem renda, sem perspectiva, sem condições de sustentar suas famílias e honrar seus compromissos no dia a dia (BRASIL, 2016).

0 sistema simbólico, construído em torno de relações de oposição e aproximação entre os pares anteriormente expostos, posiciona os indivíduos e grupos de acordo com a hierarquia que ele constitui. Observada a passagem acima, mais do que a representação em torno da crise e dos significados da despesa pública, há uma distribuição de papeis e identidades. 0 mercado é definido como gerador de renda e emprego. A economia, no entanto, requer sinais de austeridade do Estado, a quem cabe preparar as condições para o mercado. 0 Estado não é uma força capaz de induzir impactos positivos com a despesa pública, que tem, no longo prazo,

18. A rigor, distinguindo-se da maneira de representação da despesa pública aqui indicada, na já citada campanha cujo mote é "vamos tirar o Brasil do vermelho para voltar a crescer" há uma referência à expansão das despesas federais com a educação nos últimos anos. Afirma-se que as despesas cresceram 285\% acima da inflação, mas o IDEB (Índice de Desenvolvimento da Educação Básica) de 2015 mantevese estável. A campanha procura reforçar o valor negativo do Estado como solução dos problemas coletivos, sob a forma de referência a um caso concreto que equivale a mais uma operação narrativa voltada a tornar familiar a imagem do "Estado problema". A campanha fala em "muita despesa, pouco resultado". Sem aprofundar a discussão sobre educação, deve-se, contudo, chamar atenção para a natureza pouco elaborada do argumento. Eis algumas razões: o Ideb que ficou estagnado é o do ensino médio, mas os índices dos anos iniciais e finais do ensino fundamental tiveram evolução positiva, tendo sido cumprida a meta para os anos iniciais; para todas as etapas, inclusive ensino médio, a rede pública evoluiu, tendo havido redução do índice na rede privada para o ensino médio; o governo federal não é diretamente responsável pela educação básica, sendo que parcela do crescimento de seu orçamento foi destinada às redes federais de educação superior e profissional e tecnológica; as despesas em educação requerem prazo maior de maturação, em termos de reflexos sobre indicadores educacionais, não se prestando a uma análise simplista de que mais recursos não foram capazes de alterar os índices no curto prazo. Nenhum desses argumentos envolve negar os problemas da educação pública no Brasil, mas são suficientes para refutar a associação simplista entre despesa e resultados, utilizada como exemplo para persuadir a audiência acerca da visão negativa do Estado. 
efeitos neutros ou negativos. As famílias são vítimas (especialmente os pobres) da imprudência fiscal do Estado, devendo aceitar menos despesas para a economia se reorganizar. Funda-se uma hierarquia valorativa, no topo da qual se encontra o setor privado, sendo o Estado o polo passivo, que não tem atributos positivos, a não ser em sua relação com o mercado.

Entre a desordem e a ordem, repousa o pensamento econômico, postulando fazer a passagem de uma à outra. A economia convencional constrói sua visão, dispondo os termos gasto-crise em relação de associação. Nesse sentido, aquilo que aparece como linguagem científica, expondo um diagnóstico que se pretende axiologicamente neutro, pode ser lido como uma ficção, como uma representação por meio de um drama que constrói e enquadra um problema coletivo sob certo ângulo no espaço público - de um lado, reduzindo a questão econômica à fiscal; de outro, estendendo os dados econômicos à categoria familiar do "Estado problema".

Resulta da construção discursiva aqui examinada que a crise enquanto problema coletivo seria uma matéria apropriada pelas teorias econômicas ortodoxas. Sua existência no espaço discursivo é enunciada pelos próprios economistas nos campos científico e burocrático, mas traduzida para o domínio prático por representantes do poder político e pela mídia. A responsabilidade política é atribuída ao Estado, que deve conter a si próprio para produzir expectativas positivas. A responsabilidade causal radica no par gasto-crise. Menos gastos levam a expectativas de mercado positivas, com efeitos sobre a atividade econômica.

Mas a atribuição de responsabilidades só é efetiva se a perspectiva é apreendida como expressão do interesse coletivo, que deve ser lido como um signo vazio, um valor em si mesmo carente de sentido sobre o qual a narrativa incide, buscando lhe atribuir conteúdo (LÉVI-STRAUSS, 1968). A eficácia simbólica das representações requer que se reconheça (conscientemente ou não) que o limite de despesas hoje deverá reverter em mais serviços públicos adiante, em razão do aumento de renda e receita. Nesse sentido, deve-se apreender o gasto público intertemporalmente, acatando perdas no presente para ganhar no futuro. Em termos econômicos, caso o PIB cresça ao longo dos anos de vigência da $\mathrm{PEC}$, limitar a despesa primária à inflação significa (aritmeticamente) bloquear a transferência dos ganhos econômicos à sociedade sob a forma de ampliação do financiamento a serviços públicos ${ }^{19}$.

A quem apreende a questão sob a ótica da representação ofıcial, resta crer que menos é mais ${ }^{20}$. Tudo se dá como uma espécie de mágica, na medida em que, pressuposta a eficácia do esquema interpretativo, o indivíduo deve "consentir" a própria perda. Para tanto, reconhece que, se lida em conformidade com os pares que estruturam o

19. Inclusive para os pisos de aplicação em saúde e educação, na medida em que passam a estar atrelados a um percentual fixo da receita de 2017, acrescido da inflação passada. Isto é, ao longo do tempo, o crescimento real do PIB (e da receita) implica um piso de gasto que equivale a um percentual de receita do ano corrente que diminui à medida que a receita aumenta.

20. "Menor pagamento de juros [em razão da diminuição da dívida pública] resulta em redução do superávit primário necessário para manter a dívida sob controle, permitindo, em um tempo indeterminado, a expansão de programas sociais" (MENDES, 2016). Disponivel em: <http://www1.folha.uol.com.br/ilustrissima/2016/09/1815978-o-teto-de-gastos-e-a-protecao-aos-pobres.shtml>. Acesso em: 10 dez. 2016. 
sistema simbólico sob o qual se erige a PEC, ela é uma necessidade, por assim dizer, "objetiva”, que visa à realização do interesse coletivo, devendo a contenção da despesa primária reverter, futuramente, em abundância. De outro lado, enquadramentos alternativos, que reservem concepção distinta ao gasto público, são tomados como modelos que conduzem ou aprofundam a crise, ganhando o status de impensável.

Diante do exposto, resta perguntar: quem tem a autoridade para transformar perdas em ganhos? Que condições habilitam alguém a realizar predições, tomadas como socialmente válidas, numa espécie de efeito de oráculo, pelo qual se fala em nome do grupo, transformando dever-ser (indicativo) em ser (imperativo), isto é, em discurso coletivo?

\section{Autoridade como fonte da eficácia sim- bólica}

As indagações anteriores impõem que se discuta a fonte da eficácia simbólica da representação oficial. Pode-se reformular os questionamentos da seguinte maneira: a quem está delegado o poder de falar, de modo que, ao fazê-lo, é como se o interesse coletivo falasse, ganhando existência na medida em que é nomeado por alguém habilitado a fazê-lo?

Gusfield (1984) é um autor ligado à tradição construtivista, segundo a qual os agentes sociais constroem o mundo social, não o tomando como um dado ${ }^{21}$. Seu foco é a reconstrução das operações pelas quais os agentes criam definições para os fenômenos. No entanto, a eficácia simbólica das palavras não está radicada apenas na narrativa costurada pelos agentes. De certo modo, os discursos encontram o espaço social estruturado, tanto em relação aos modos de expressão consagrados, como a uma distribuição assimétrica do poder de falar. Portanto, nem todo mundo fala o que quer, a todo o momento ${ }^{22}$. A eficácia social da palavra requer a concentração de um recurso simbólico de autoridade pelo qual a audiência tende a crer naquilo que está sendo enunciado e em quem está enunciando.

0 Estado é um sistema simbólico, poder estruturante que constitui categorias ao nomeá-las como oficiais. Ele se faz acompanhar de uma submissão espontânea ao existente, sendo o fundamento de uma percepção lógica comum aos agentes em razão da qual eles aderem à ordem ${ }^{23}$ (BOURDIEU, 2014). O Estado emprega o monopólio da nomeação, autorizando um ponto de vista na medida em que lhe imputa o caráter oficial, cuja validade só se dá na condição de ser representado como desinteressado.

Por outro lado, é preciso indagar pelos agentes que concentram este recurso específico, pelo qual se pode falar em nome do universal, no limite, fazendo existir o grupo ao falar em seu nome. A constituição do Estado é inseparável da construção dessa categoria de agentes sociais que se apro-

21. "Os teóricos seminais aqui são George Herbert Mead (1934) e Alfred Schutz (1967). 0 que essa perspectiva faz é enfatizar a atividade do ator humano de criar e construir o mundo em que ele vive (GUSFIELD, 1984, p. 18)".

22. Foucault (2008) se refere a uma rarefação dos sujeitos que falam.

23. Percepção comum que funda a integração social, mas também estabelece as condições para o dissenso, na medida em que permite o entendimento mútuo sobre princípios básicos de nomeação da realidade social, pré-condição para o conflito. 
priam do poder de falar em nome de todos. 0 Estado investe tais agentes na condição de representantes do interesse geral, dotando-os de um estoque de palavras e formas socialmente associadas aos atos estatais desparticularizados. Ao mesmo tempo, os agentes oficiais também constituem o Estado ao constituírem a si próprios, criando as teorias do interesse universal, as formas pelas quais o desinteresse é expresso e as maneiras como se pode falar de algo.

0 olhar para a dramatização envolvida na construção dos problemas públicos deve ser articulado à distribuição do capital de reconhecimento no espaço social e do poder de nomear o ponto de vista oficial. Para tanto, é necessário apreender a estrutura do espaço social na qual os agentes constroem suas narrativas, analisando como agentes estatais e não-estatais estabelecem relações, lutando pela imposição de princípios de visão e divisão social legítimos, que autorizam pontos de vista mais ou menos inclinados a cada grupo (BOURDIEU, 2014).

No caso da PEC 241, o aspecto a salientar em relação aos diferenciais de poder simbólico é a combinação da autoridade científıca e burocrática dos economistas para formular diagnósticos que revertem na dramatização de problemas públicos. As representações daí derivadas procuram emprestar legitimidade à ação governamental. É o modo de pensamento economicista (mais do que dos economistas) que sustenta a versão. Nele, o mundo social é tomado como consequência do modelo econômico, de forma que as sociedades devem se adap- tar à lógica inexorável de mercado, sob a pena da desorganização de suas relações.

0 diagnóstico dominante da crise brasileira é feito sob esse pressuposto, tendo no gasto público a raiz do problema. A despesa governamental é representada como agregado macroeconômico que afeta negativamente as expectativas dos agentes. Podese falar em uma luta de representações, de modo que, por exemplo, os sentidos atribuídos ao piso de financiamento obrigatório de serviços públicos, no âmbito de setores como saúde e educação, passam a ser lidos como compromissos que oneram o Estado e produzem rigidez, e não como uma condição de estabilidade para o funcionamento dos sistemas de proteção social.

Discursos e práticas institucionais se entrecruzam. Não apenas se produzem os enunciados do interesse público como austeridade, como são criadas regras fiscais que funcionam como limites e proibições, exercendo-se uma disciplina sobre as despesas públicas que a PEC cuidaria de exacerbar. 0 poder das palavras nomearem os princípios legítimos de visão social se articula a um conjunto de instituições, como agências de risco e regras de controle de despesas que inscrevem nas práticas sociais esquemas avaliativos da gestão fiscal ${ }^{24}$.

Os princípios de visão e divisão estabelecidos se tornam eficazes ao sancionarem as nações cujos modelos econômicos se distanciam de suas prescrições. Tais sanções assumem a forma de remuneração mais elevada pelo financiamento de suas dívidas e redução de graus de investimen-

24. Aqui se procura salientar menos o fato de que há limites à despesa pública, e mais a forma como determinadas práticas institucionais materializam uma representação geral da despesa pública como uma negatividade, sem levar em conta, por exemplo, regras mais flexíveis para momentos em que o gasto público possa constituir uma válvula de escape às restrições sociais e econômicas. 
to. Como num passe de mágica, convertese o poder de predizer em poder de fazer coisas, tomar atitudes e propor mudanças. A autoridade de enunciar os princípios da boa política econômica reverte no poder de impactar a economia de um país ou as possibilidades de ação dos governos, em caso de distanciamento em relação ao modelo. Cabe chamar atenção para a materialidade do discurso, na medida em que o ponto de vista oficial se objetiva em práticas que tendem a ser naturalizadas e a produzir classificações que incidem sobre governos e indivíduos.

0 sistema de significados posiciona hierarquicamente também os agentes em função de seus pontos de vista e de seus recursos, na medida em que estejam mais ou menos próximos da definição oficial do interesse coletivo. Os economistas ortodoxos não apenas postulam, sob a forma de autoridade científica e burocrática, o monopólio do poder de nomear as razões da crise, como também o conhecimento dos instrumentos necessários para superá-la, legitimando-se para ocupar os postos governamentais que controlam os canais de decisão estatal. 0 capital de palavras, pelo qual se detêm os conceitos reconhecidos como expressões conformes à lógica do interesse público, é também um capital de soluções, sobretudo em situações de crise (BOURDIEU, 2014). É assim que se pode passar do pensamento econômico ao campo burocrático, de modo que a linguagem econômica convencional tende a concentrar, dentro dos espaços institucionais monopolizados pelos seus saberes, reconhecimento de que está apta a falar em nome do público e a indicar as soluções socialmente aceitáveis.

As soluções, entretanto, não decorrem do potencial técnico-analítico da teoria, apta a desvendar a realidade econômica fe- nomênica, mas do fato de que categorias de percepção se impõem como princípios de visão social legítimos, lastreados na autoridade científica e burocrática. É por meio dessa soma de recursos que se criam as condições para transmutar uma perspectiva específica em interesse universal e no poder de falar em nome de todos ("nós temos a saída”, "precisamos fazer sacrifícios" e assim por diante), assumindo-se um sujeito coletivo abstrato.

0 trabalho de uma teoria social das representações aplicada aos problemas públicos requer que se reconstruam as estruturas simbólicas, no interior das quais os termos e as relações que estabelecem entre si ganham significados determinados e orientam condutas públicas. Diante do efeito de coerência que os sistemas produzem, suas palavras tendem a ganhar eficácia e performaticamente atribuir sentidos às coisas na medida em que são representadas como evidências, alinhadas à percepção socialmente compartilhada do "cidadão comum". Particularmente, o efeito de evidência que as narrativas oficiais produzem, baseadas em saberes científicos autorizados, implica que sistemas teóricos alternativos são classificados como o “impensável”. Isto é, como aquilo que está fora dos limites do interesse coletivo, não podendo, portanto, ser integrado ao jogo de representações dos problemas públicos.

No caso da PEC 241, o não reconhecimento das perspectivas alternativas se dá sob a forma da inevitabilidade da limitação dos gastos públicos por vinte anos, pois, diante da narrativa oficial, tudo o mais implica aproximar-se do dia do "juízo fiscal" ${ }^{25}$. O senso de urgência do limite de gasto como recuperação da ordem social só é inteligível diante da reflexão sobre as condições de efıcácia do discurso oficial, 
desnaturalizando classificações e problematizando a concentração de autoridade para nomear os problemas públicos. 0 que é particularmente relevante, diante da combinação de autoridade burocrática e científica da economia convencional. É ela que oferece lastro ao trabalho de codificação, que consiste em colocar a palavra oficial na devida forma, conferindo-lhe aparência racional e desinteressada, de modo a criar a conduta socialmente aceitável, em termos de gestão pública (BOURDIEU, 1990).

Com base em seu crédito social, a ortodoxia econômica confere existência ao inominável (àquilo que não se pode dizer no espaço público), transfigurando redução do financiamento às políticas demandadas pela população em prudência fiscal, pensada como instrumento para alcançar a or$\mathrm{dem}^{26}$. Esse ato de magia requer todo um trabalho pelo qual se converte uma perspectiva singular (da economia convencional) em palavra desinteressada, habilitada a definir os problemas coletivos e a empregar soluções socialmente homologadas. 0 que só se faz mediante a constituição do público enquanto categoria cognitiva e mo- ral, fixando a austeridade como fronteira que define a ação em nome do interesse coletivo. Essa autoridade se transfigura em ocupação dos postos estratégicos no campo estatal por aqueles que detêm os saberes econômicos, mas também no controle das decisões governamentais, aplicando sobre quaisquer temas administrados pelo Estado a racionalidade econômica e fiscal, sob a forma de controle dos gastos como encarnação do universal.

É dessa forma que se associa congelamento das despesas primárias por vinte anos à solução para a crise. A nova regra fiscal repercutirá sobre seis mandatos presidenciais, durante os quais os ganhos econômicos não serão repassados ao financiamento de serviços públicos (saúde, educação, segurança, entre outros). Nesse sentido, a PEC reforça o estilo tecnocrático de gestão, ao blindar as decisões econômicas em relação ao desejo coletivo, fabricado em meio aos canais de veiculação e processamento das demandas sociais e do sistema político e eleitoral. Resta saber se o capital de credibilidade da economia convencional será suficiente, ao longo do tempo, para

25. 0 que não implica aceitação automática em relação à medida. 0 próprio site do Senado Federal mostra consulta pública em que a PEC do teto de gastos é rejeitada por 93\% dos que se manifestaram. No entanto, ainda que haja desaprovação de determinada prática pública, o que se pretende mostrar aqui é como os agentes procuram legitimá-la, criando uma cultura dos problemas públicos e fabricando um domínio do universal (daquilo que é coletivo, que transcende o particular) que autoriza certas práticas e soluções para os problemas, nos termos em que são representados.

26. Vale ilustrar o argumento, mostrando como o pensamento ortodoxo opõe crescimento econômico e proteção social, reivindicando o poder de atribuir conteúdo à maturidade social, definida como ajuste dos desejos coletivos à racionalidade econômica. "Entendemos que vigora na sociedade brasileira desde a promulgação da constituição em 1988 um contrato social que requer a contínua elevação do gasto público como proporção do PIB. Isto é, o contrato social demanda que a receita tributária cresça além do crescimento do produto. Nossa impressão é que a sociedade não está madura ainda para discutir com profundidade ajustes no contrato social. É por este motivo que cremos que a saída será por novas rodadas de elevação da carga tributária. Reformas mais profundas do contrato social requererão um desejo muito forte por parte da sociedade em acelerar o crescimento" (BARBOSA FILHO; PESSOA, 2014, p. 27-29). 
legitimar a racionalidade econômica entregue a si mesma, cristalizando nas práticas institucionais a articulação entre ordem pública e austeridade, ou se agentes sociais acumularão crédito para recriar a ordem simbólica, desconstruindo a oposição entre despesa pública e interesse universal.

\section{Considerações finais}

A representação do problema público encerra uma dimensão teatral, constituindo-se em meio a um drama em que a narrativa se vale de uma série de operações para se apresentar como definição bem fundamentada das questões coletivas. A autorização da versão oficial pressupõe o poder dos agentes em criar uma ordem pública que fixa categorias cognitivas e morais, restituindo, no caso em análise, a "normalidade" da sociedade fraturada pelo déficit fiscal.

No caso da PEC 241, o sistema simbólico se institui em torno da associação entre gasto-crise e das oposições imprudência fiscal $x$ crescimento econômico e Estado $\mathrm{x}$ mercado. Culmina da articulação entre esses elementos a construção performática da PEC 241 como meio de conexão entre a desordem e a ordem. 0 discurso procura constituir-se em meio a um esquema interpretativo de corte economicista, valendo-se da combinação de autoridade burocrática e científica, postulada pela teoria econômica ortodoxa, cujas visões informam o discurso governamental e parte substantiva da narrativa da mídia.

Apesar da distribuição assimétrica do capital de palavras e do poder de apresentar soluções em circunstâncias de crise, a imposição da visão legítima do mundo social sempre é objeto de lutas. Ainda que num contexto de aliança de poderes científicos, burocráticos, políticos e midiáticos, os detentores do poder nunca obtêm controle absoluto da palavra oficial. Sempre há conflitos pelo poder de nomear o problema público (BOURDIEU, 1990).

0 conflito envolve a capacidade de forças sociais expressarem outros sentidos atribuídos à crise, desnaturalizando a associação espontânea do par gasto $x$ crise. A luta pelo poder de renomear a crise requer que se desfaça a imagem estigmatizada do gasto público, bem como se desconstituam os princípios de visão social fixados pelo discurso oficial. A abertura do espaço de possibilidades para apreensão de outros sentidos na discussão sobre a crise implicaria redistribuir o poder de construir diagnósticos, ofertar soluções e, principalmente, desnaturalizar a tese de que o ônus da crise deve recair sobre os usuários dos serviços públicos.

Entre o dia do juízo fiscal e o congelamento de gastos que desfinancia políticas públicas demandadas pela população, outras respostas à crise são possíveis. Mas elas só se afırmarão no espaço público se, num trabalho simultaneamente político e cognitivo, as forças sociais contrárias à narrativa oficial, lastreada nos saberes econômicos convencionais, forem capazes de produzir representações reconhecidas como expressão do interesse geral. Dessa maneira, poderão inscrever a despesa pública em um sistema de significados e valores alternativos, cujos termos desfaçam a associação gasto $\mathrm{x}$ crise e autorizem publicamente a adoção de soluções que reforcem, especialmente, o sistema brasileiro de proteção social, apreendido em suas conexões com o bem-estar coletivo, e não apenas como atributo estigmatizante que eleva o nível da despesa pública. 


\section{Referências}

BARBOSA FILHO, F. H. A crise econômica de 2014/2017. Estudos Avançados, v. 31, n. 89, p. 51-60, 2017.

BARBOSA, N. Amnésia seletiva. Blog do IBRE. Disponivel em: <http://blogdoibre.fgv.br/posts/cargatributaria-dividendos-e-amnesia-seletiva>. Acesso em: 17 set. 2017.

BARBOSA FILHO, F. H.; PESSOA, S. Desaceleração recente da economia. In: Sob a luz do Sol: uma agenda para o Brasil, CDPP, 2014, p. 15-30 (coletânea de capítulos).

BORDWELL, D. Estudos de cinema hoje e as vicissitudes da grande teoria. In: RAMOS, F. R (Org.) Teoria contemporânea do cinema: pós-estruturalismo e filosofia analítica, v. 1, São Paulo: Senac, 2014.

BOSCHI, R; GAITÁN, F. Intervencionismo estatal e políticas de desenvolvimento na América Latina. Caderno CRH, Salvador, v. 21, n. 53, p. 305-322, maio/ago. 2008.

BOURDIEU, P. Coisas ditas. São Paulo: Brasiliense, 1990.

Sobre o Estado. São Paulo: Companhia das Letras, 2014.

BRASIL. EMI n ${ }^{\circ}$ 00083/2016 MF MPOG. Disponivel em: <http://www.planalto.gov.br/ccivil_03/ Projetos/ExpMotiv/EMI/2016/83.htm>. Acesso em: 10 dez. 2016.

BRASIL. Proposta de Emenda à Constituição $\mathbf{n}^{0}$ 241/2016. Altera o Ato das Disposições Constitucionais Transitórias, para instituir o Novo Regime Fiscal. Disponivel em: <http://www.planalto. gov.br/ccivil_03/Projetos/PEC/2016/msg329-junho2016.htm>. Acesso em: 10 dez. 2016.

BRASIL. Câmara dos Deputados. Relatório da Comissão Especial destinada a proferir parecer à Proposta de Emenda à Constituição no 241-A, de 2016, do Poder Executivo, que "altera o Ato das Disposições Constitucionais Transitórias, para instituir o Novo Regime Fiscal”. Disponível em: <http://
www.camara.gov.br/proposicoesWeb/prop_mostrarintegra? codteor $=1496778 \mathrm{Ct}$ filename $=\mathrm{SB}$ $\mathrm{T}+3+\mathrm{PEC} 24116+\% 3 \mathrm{D} \% 3 \mathrm{E}+\mathrm{PEC}+241 / 2016>$. Acesso em: 10 dez. 2016.

BRASIL. Na TV, Henrique Meirelles explica necessidade do teto dos gastos públicos. Disponível em: <http://www.brasil.gov.br/economia-e-emprego/2016/10/na-tv-henrique-meirelles-explicanecessidade-do-teto-dos-gastos-publicos $>$. Acesso em: 10 dez. 2016.

CODATO, A. N. C. Sistema estatal e política econômica no Brasil pós-64. São Paulo: Hucitec/ Anpocs, 1997.

DELEUZE, G. A imagem-tempo. São Paulo: Brasiliense, 2005.

Lógica do sentido. São Paulo: Perspectiva, 2015.

DWECK, E.; TEIXEIRA, R. A. A política fiscal do governo Dilma e a crise econômica. Texto para Discussão. IE - Instituto de Economia, Campinas, n. 303, jun. 2017.

DINIZ, E. Globalização, reforma do Estado e teoria democrática contemporânea. São Paulo em Perspectiva, v. 15, n. 4, p. 13-22, 2001.

FOUCAULT, M. A ordem do discurso. São Paulo: Loyola, 2008.

GOBETTI, S. W.; AMADO, A. M. Ajuste fiscal no Brasil: algumas considerações de caráter pós-keynesiano. Revista de Economia Política, v. 31, n.1 (121), p. 139-159, jan./mar. 2011.

GOBETTI, S.W; ORAIR, R.0. Progressividade tributária: a agenda negligenciada. Texto para Discussão. IPEA, n. 2190, abril. 2016.

GOFFMAN, E. A representação do eu na vida cotidiana. Petrópolis: Vozes, 2005.

GRÜN, R. A dominação financeira no Brasil contemporâneo. Tempo Social, v. 25, n. 1, p. 179-213, 2013.

GUSFIELD, J. The culture of public problems: drinking-driving and the symbolic order. Chicago: The University of Chicago Press, 1984. 
HOLANDA, S. B. Raizes do Brasil. São Paulo: Companhia das Letras, 2003.

LÉVI-STRAUSS, C. Introdução à obra de Marcel Mauss. In: COELHO, E. P. (Org.) Estruturalismo: antologia de textos teóricos. Lisboa: Portugália, 1968, p. 149-190.

LOUREIRO, M. R. A participação dos economistas no governo. Análise, v. 17, n. 2, p. 345-359, jul./ dez. 2006.

LOUREIRO, M. R.; LIMA, G. T. A internacionalização da ciência econômica no Brasil. Revista de Economia Política, v. 14, n. 3 (55), p. 31-50, jul./ set. 2011.

MEIRELLES, H. PEC 241/2016 e o novo regime fiscal do Brasil. Disponível em: <http:// www.fazenda.gov.br/centrais-de-conteudos/ apresentacoes/2016/2016-08-24-apresentacao-pec-241-2016-ministro>. Acesso em: $10 \mathrm{dez}$. 2016.

MENDES, M. 0 teto dos gastos e a proteção aos pobres. Ilustríssima. Folha de São Paulo. Disponível em: <http://www1.folha.uol.com.br/ilustrissima/2016/09/1815978-o-teto-de-gastos-e-a-protecao-aos-pobres.shtml>. Acesso em: 10 dez. 2016.

MOSCOVICI, S. Representações sociais. Petrópolis: Vozes, 2012.

PIRES, M. C. C. Relatório de análise dos gastos públicos federais. Disponivel em: <http:// fazenda.gov.br/centrais-de-conteudos/apresentacoes/2016/2016-05-10_relatorio-de-analise-dosgastos_site.pdf>. Acesso em: $10 \mathrm{dez} .2016$.

SERRANO, F; SUMMA, R. Demanda agregada e a desaceleração do crescimento econômico brasileiro de 2011 a 2014. Center for Economic and Policy Research, ago. 2015.

SOUZA, J. A tolice da inteligência brasileira: ou como o país se deixa manipular pela elite. São Paulo: Leya, 2015.

ZITTOUN, P. The political process of policymaking: a pragmatic approach to public policy. Houndmills, Basingstoke: Palgrave Macmillan, 2014.
ZIZEK, S. Como ler Lacan. Rio de Janeiro: Zahar, 2006. 


\section{RESUMO}

Este artigo aborda a retórica oficial e seus argumentos para a aprovação da Emenda à Constituição (PEC 241/2016), que impõe limite para o crescimento dos gastos públicos por vinte anos, correspondente à inflação do período anterior. Procura-se mostrar que os problemas públicos são construídos por meio de operações linguísticas que transformam dados em representações sociais, elaborando definições coletivas que autorizam escolhas politicas. Essas definições postulam legitimidade com base na autoridade burocrática e científica da economia ortodoxa. No caso da PEC 241, seus defensores procuram legitimá-la mediante a articulação discursiva entre gasto e crise. Será visto que a eficácia simbólica de uma linguagem do domínio público (no qual se definem os problemas sociais e suas soluções, em correspondência com uma ordem simbólica) requer que se reconheça que o agente oficial tem a autoridade de falar e agir em nome do coletivo. Consequentemente, a luta pelo controle dos instrumentos de ação socialmente homologados está associada à capacidade de nomear o que é o interesse público.

\section{PALAVRAS-CHAVE}

PEC 241; Palavra oficial; Economia ortodoxa; Problemas públicos; Representações sociais.

\section{ABSTRACT}

This article deals with the official rhetoric and its arguments for approving a constitutional amendment (PEC 241/2016) that imposes a limit to growth of public expenditures for twenty years, corresponding to the inflation rate of past period. We show that public problems are constructed by linguistic operations that transform data into social representations, elaborating collective definitions that authorize public choices. These definitions claim legitimacy based on bureaucratic and scientific authority of mainstream economics. The defenders of PEC 241 intend to legitimate it by a discursive articulation between expenditure and crisis. We will see that symbolic efficacy of a language of public domain (in which are defined the social problems and their solutions, in correspondence with a symbolic order) requires the recognition that the official agent has the authority of speaking and acting in the name of the collective. Consequently, agents fight for controlling the socially homologated instruments of action and the capacity of nominating what is the public interest.

\section{KEYWORDS}

PEC 241. Official word. Mainstream economics. Public problems. Social representations. 
